ISSN: 0377-6395
e-ISSN: 2651-4214

\title{
Etlik piliçlerde sülfadiazinin farmakokinetiği üzerine çinkonun etkisi**
}

\author{
Ramazan UZUN ${ }^{a *}$, Emine BAYDAN \\ ${ }^{a}$ Sağllk Bakanllğgl, Halk Sağllğg Genel Müdürlüğ̈̈, Ankara, Türkiye \\ ${ }^{b}$ Ankara Üniversitesi, Veteriner Fakültesi, Farmakoloji ve Toksikoloji Anabilim Dall, Ankara, Türkiye
}

MAKALE BILGISI:
ARTICLE
INFORMATION:
Geliş / Received:
10 Aralık 18
10 December 18
Kabul/Accepted:
21 Aralık 18
21 December 18
Anahtar Sözcükler:
Çinko
Etlik piliç
Farmakokinetik
Sülfadiazin
Keywords:
Broiler
Pharmacokinetics
Sulphadiazine
Zinc

ÖZET:

Bu çalışmanın amacı, etlik piliçlerde kursak ve damar içi (Dİ) yolla tek doz (100 mg/kg) uygulanan sülfadiazin ile yemde çinko ile birlikte uygulanan sülfadiazinin farmakokinetiğini belirlemektir. Çalışmada 31 günlük 40 etlik piliç kullanıldı. Civciv olarak alınan hayvanlar 25 gün boyunca hiç bir ilaç katkısı bulunmayan yemle beslendi. Bu süre sonunda piliçler 4 gruba ayrıldı; Grup 1'e ve 2'ye kontrol yemi, Grup 3 ve 4'e 200 ppm çinko katılmış yem 5 gün boyunca verildi. Grup 1'deki hayvanlara sülfadiazin $100 \mathrm{mg} / \mathrm{kg}$ dozunda Dİ verildi. İlaç verilmesini takiben 5., 15., ve 30. dakikalar ile 1., 2., 4., 6., 8., 12., 18. ve 24. saatlerde heparinli tüplere birer $\mathrm{ml} \mathrm{kan} \mathrm{alındı.} \mathrm{Grup} \mathrm{2'ye} \mathrm{ve} \mathrm{3'e} 100 \mathrm{mg} / \mathrm{kg}$ sülfadiazin süspansiyon hâlinde bir sonda yardımı ile doğrudan kursağa verildi. Grup 4'e ise $100 \mathrm{mg} / \mathrm{kg}$ dozunda sülfadiazin içme suyuna katılarak verildi. Her üç gruptan da Dİ uygulamada olduğu gibi (5. dakika hariç) heparinli tüplere kan alındı. Santrifüjle ayrılan plazmalardan ilaç yoğunluğu spektrofotometrik yöntemle belirlendi. Plazma ilaç yoğunluğu zaman eğrisi iki bölmeli dışa açık modeli gösterdi. Etlik piliçlerde ilacın biyoyararlanımı (F), 200 ppm çinkolu ve çinkosuz yemle besleme durumuna göre önemli farkl11ıklar gösterdi (Grup 2'de \% 91,97; Grup 3’te \% 64,14; Grup 4'te \% 60,81).

\section{The effect of zinc on pharmacokinetics of sulphadiazine at broilers}

\begin{abstract}
:
The aim of this study is to determine the pharmacokinetics of sulphadiazine that administered intravenously (iv) and via gizzard at a single dose of $100 \mathrm{mg} / \mathrm{kg}$, and to find out whether there is an interaction between sulphadiazine and zinc when applied combined in feed. Totally 40, 31-day old broilers were used. Chicks were fed without medication for 25 days. At the end of this period the chickens were divided into 4 groups; control feed to Group 1 and 2, 200 ppm zinc added feed to Group 3 and 4 were given for 5 days. Sulphadiazine was administered at a single dose of $100 \mathrm{mg} / \mathrm{kg}$ intravenously to the Group 1. After the injection of the drug, $1 \mathrm{ml}$ blood was taken into heparinized tubes at 5., 15. and 30. minutes and 1., 2., 4., 6., 8., 12., 18. and 24. hours. Group 2 and 3 were given suspension of sulphadiazine into gizzard. Group 4 was administered $100 \mathrm{mg} / \mathrm{kg}$ sulphadiazine in drinking water. In all 3 groups, the same protocol as described in IV application (except for 5th minute) was used, blood was taken into heparinized tubes from all 3 groups. The drug density was determined by spectrophotometric method from the plasma separated by centrifuge. Plasma drug concentration - time curve showed two-compartment open model. There were significant differences in terms of bioavailability (F) of the broiler chickens with $200 \mathrm{ppm}$ zinc added feed and feed without zinc ( $91,97 \%$ in Group 2; $64,14 \%$ in Group 3; 60,81\% in Group 4).
\end{abstract}

\footnotetext{
**Bu çalışma aynı isimli doktora tezinden özetlenmiştir.

* Sorumlu yazar / Corresponding author

eposta adresi/e-mail address: ramazanuzun60@gmail.com
} 


\section{Giriş}

Sülfonamidler, bakterilerin sebep olduğu enfeksiyonların tedavisinde ve önlenmesinde sistemik olarak kullanılan ilk ilaçlardır. Penisilinlerin tedaviye girmesinden önce bakterilere karşı kullanılan en önemli kemoterapötik ilaçlar olan sülfonamidler, esas olarak para-aminobenzensulfonamidin (sülfanilamid) türevleridir. Sentetik olarak hazırlanan sülfonamidlerin, şimdiye kadar beş binin üzerinde türevi sentezlenmiş olup bugün için 25-30 kadarı tedavide kullanılmaktadır $(15,16,23)$.

Son yıllarda sülfonamidlerin kullanımı, yumurta veriminde azalmaya sebep olması ve tedavi alanına birçok antibiyotiğin girmesinden dolayı eskiye göre sınırlanmıştır $(12,16)$. Bununla birlikte, özellikle kombinasyon hâlinde etki spektrumlarının geniş olması (26), sürü hastalıklarının tedavisi ve korunmasında kolay bir şekilde uygulanabilmeleri, ucuz olmaları gibi avantajlarından dolayı kanatlılar da dahil, diğer evcil hayvanların hastalıklarının tedavisi ve korunmasında halen geniş bir şekilde kullanılmaktadırlar $(1,6,10,18,22)$.

Sülfonamidlerin bir üyesi olan sülfadiazinin bazı metallerle kompleks yapabilme özelliğinin bulunması, hayvan yemlerinde bulunan minerallerin de tedavi amaciyla kullanılan sülfonamidlerle etkileşime girme ihtimalini akla getirir. Ancak, yapılan literatür taramalarında sülfonamidlerin metallerle etkileşip etkileşmediğine yönelik çalışmaların çok sınırlı olduğu görülmektedir $(4,5)$.

Literatür bilgiler doğrultusunda çinko ile sülfadiazin arasında in vitro kompleks oluştuğu bilinmektedir (5). Çinkonun kanatlı yemlerine sürekli olarak katılması ve çinko ile sülfadiazin arasında in vitro kompleksin oluşması, in vivo şartlarda da böyle bir kompleksin oluşabileceği fikrini akla getirmektedir. Bu düşünceden hareketle, araştırmada, etlik piliçlerde sülfadiazin ve çinko arasında in vivo şartlarda herhangi bir etkileşim olup olmadığı hususunun farmakokinetik parametreler aracılığında belirlenerek çinko ve sülfadiazinin kanatlılara koruyucu ve tedavi edici amaçla verilirken bir arada kullanılıp kullanılamayacağına bir açıklık getirilmesi amaçlanmıştır.

\section{Gereç ve Yöntem}

Çalışmada ROS PM 3 ırkı civcivler kullanıldı. Bir günlük civcivler hiç bir ilaç veya aşı uygulaması yapılmadan alındı. Civcivlerin bakımları ve beslenmeleri, ilk hafta $30^{\circ} \mathrm{C}$, diğer günlerde ise $24^{\circ} \mathrm{C}-29^{\circ} \mathrm{C}$ ssıya ve $\% 60-65$ neme $(2$, $3,13)$ sahip uygun ortamlarda gerçekleştirildi. Civcivler, 25 gün boyunca hiç bir ilaç katkısı bulunmayan yemle beslendi. Bu süre sonunda bir gün süreyle aç bırakılan hayvanlar, her birinde 10 hayvanın bulunduğu 4 gruba ayrıldı. Grup 1 ve 2'ye içinde hiç bir katkı maddesi bulunmayan etlik piliç yemi, Grup 3 ve 4'e ise içine 200 ppm çinko (Çinko sülfat, $\mathrm{ZnSO}_{4} .7 \mathrm{H}_{2} \mathrm{O}$, Merck 5273522) karıştırılarak (21) hazırlanan yem 5 gün boyunca verildi. Çalışma sırasında da hayvanlar bu yemleri almaya devam etti. Ortalama $1 \mathrm{~kg}$ canlı ağırlığa ulaşıldığında denemeye başlandı.

Grup l'deki hayvanlara canlı ağırlık göz önünde tutularak (100 mg/kg dozunda) ve toplam hacim 2,5 ml olacak şekilde ayarlanan ilaç, sağ kanat altı toplardamarından (Vena cutenea ulnaris) verildi (13). İlacın verilmesini takiben 5., 15. ve 30. dakikalar ile 1., 2., 4., 6., 8.,12., 18. ve 24. saatlerde sol kanat altı toplardamarından heparinli (1 ml kan için 50 ünite heparin) tüplere $(7,9,13)$ birer $\mathrm{ml}$ kan alındı.

Grup 2'ye ilaç, kursağa toplam hacim 2,5 ml olacak şekilde ayarlanarak süspansiyon hâlinde verildi. Önce her hayvan için hazırlanan temiz enjektörlere hayvanın canlı ağırlı̆̆ına göre tartılan (100 mg/kg sülfadiazin olacak şekilde) baz sülfadiazin konuldu. Üzerine süspansiyon oluşturacak şekilde $(1 \mathrm{ml})$ deiyonize su çekildi. İyice karışması sağlandıktan sonra, sonda yardımı ile doğrudan hayvanların kursağına verildi. Sondada ilaç kalma ihtimalini gidermek için sonda 1,5 ml deiyonize su ile yıkandı. İlacın verilmesini takiben 15. ve 30. dakikalar ile 1., 2., 4., 6., 8., 12., 18. ve 24. saatlerde damar içi uygulamada olduğu gibi heparinli tüplere $(7,9,13)$ birer ml kan alındı.

Grup 3'te bulunan hayvanlardaki uygulama, yemlerine 200 ppm çinko katılması dışında, Grup 2'de olduğu gibi yapildi $(7,9,13)$.

Grup 4'deki hayvanlar uygulamaya geçmeden önce bir gece susuz bırakıldı. Hayvanların toplam canlı ağırlığına göre $(100 \mathrm{mg} / \mathrm{kg})$ baz sülfadiazin tartılıp bir litre suya karıştırılarak hayvanlara verildi. Bu hesap hayvanların günlük tüketebileceği yem miktarının (100 g) iki katı su tüketeceği (200 ml) ilkesinden hareketle yapıldı (2, 3). Ancak, ilaçlı suyun kısa sürede tüketilebilmesi için günlük su alım miktarının yarısı verildi. İlacın dibe çökmemesi için ilaçı su 
aralıklarla karıştırıldı. İlaçlı su hayvanlar tarafindan iki saatte tüketildi. İlaçlı suyun tüketilmesini takiben 15. dakikadan başlanarak diğer gruplarda olduğu gibi hayvanlardan heparinli tüplere $(7,9,13)$ birer ml kan alındı.

Hayvanlardan alınan kanlar 3000 devirde 5 dakika santrifüj edildi. Plazmalar ependorf tüplerine alınarak test edilinceye kadar (1 ay) $-18{ }^{\circ} \mathrm{C}^{\prime}$ de tutuldu (13).

Plazma sülfadiazin analizleri Reider (20) tarafindan geliştirilen yönteme göre yapıldı. Hayvanlara verilen yem ham maddelerinde topraktan gelebilecek çinko ile sudaki çinko düzeylerini belirlemek için Williams (27) tarafından belirlenen yöntem kullanıldı.

Farmakokinetik değişkenler, Wagner (25) tarafından bildirilen standart eşitlikleri esas alan, PKCALC ve $G W$ BASIC 2.02 bilgisayar programlarına göre, ilacın biyoyararlanımı $(\mathrm{F})$ değeri ise $\mathrm{F}=$ Eğri Altındaki Alan (EAA) kursak veya içme suyu $/ \mathrm{EAA}_{\mathrm{Di}}$ formülünden (14) hesaplandı.

İstatistik hesaplamalarda SPSS 8.0 programı kullanıldı. Farmakokinetik değişkenler arasındaki önemlilik de Independent-Samples $t$ Testi’ne göre yapıldı; $\mathrm{p}<0,05$ farklılı önemli olarak değerlendirildi.

Araştırmanın planlandığı sıralarda, ülkemizde hayvan deneyleri için etik kurul izni gerekmediğinden, çalışmaya başlanması için bir etik kurul raporu alınmış olmamakla birlikte, çalışma, etik konusundaki bilimin gerektirdiği bütün kurallar dikkate alınarak yapılmıştır.

\section{Bulgular}

Hayvanlara verilen yem ham maddelerindeki çinko düzeyi 28,3 ppm, sudaki çinko düzeyi ise 0,1 ppm olarak bulunmuştur.

Çalışma gruplarından Grup 1'e ait plazma ilaç yoğunluklarının aritmetik ortalamaları Tablo 1'de, plazma ilaç yoğunluğu zaman eğrisi Şekil 1'de, farmakokinetik değişkenler Tablo 2'de; Grup 2'ye ait plazma ilaç yoğunluklarının aritmetik ortalamaları Tablo 3'te, plazma ilaç yoğunluğu zaman eğrisi Şekil 2'de, farmakokinetik değişkenler ise Tablo 4'te verilmiştir.

Tablo 1: Etlik piliçlere $100 \mathrm{mg} / \mathrm{kg}$ dozunda Dİ verilen sülfadiazine ait (Grup 1) plazma ilaç yoğunluklarının aritmetik ortalamas1 (Ortalama \pm Standart hata).

Table 1: The arithmetic mean of plasma drug levels of sulphadiazine of $100 \mathrm{mg} / \mathrm{kg}$ given intravenous to broilers (Group 1) (Mean \pm Standard error).

\begin{tabular}{lcc}
\hline Zaman & Ortalama \pm Standart hata $(\boldsymbol{\mu g} / \mathbf{m l})$ & En alt-en üst değerler $(\boldsymbol{\mu g} \mathbf{g} \mathbf{m l})$ \\
\hline 5. dakika & $197,50 \pm 8,40$ & $183,20-206,60$ \\
15. dakika & $165,47 \pm 2,44$ & $158,40-174,80$ \\
30. dakika & $143,77 \pm 2,55$ & $129,00-156,90$ \\
1. saat & $127,33 \pm 2,41$ & $113,50-139,80$ \\
2.saat & $110,83 \pm 3,12$ & $100,30-126,60$ \\
4. saat & $72,71 \pm 1,95$ & $62,30-81,70$ \\
6. saat & $57,97 \pm 0,27$ & $56,80-59,20$ \\
8. saat & $42,42 \pm 1,69$ & $36,70-53,00$ \\
12.saat & $29,44 \pm 0,48$ & $26,70-32,10$ \\
18. saat & $16,24 \pm 0,36$ & $14,30-18,10$ \\
24. saat & $6,45 \pm 0,10$ & $5,70-6,80$ \\
\hline
\end{tabular}




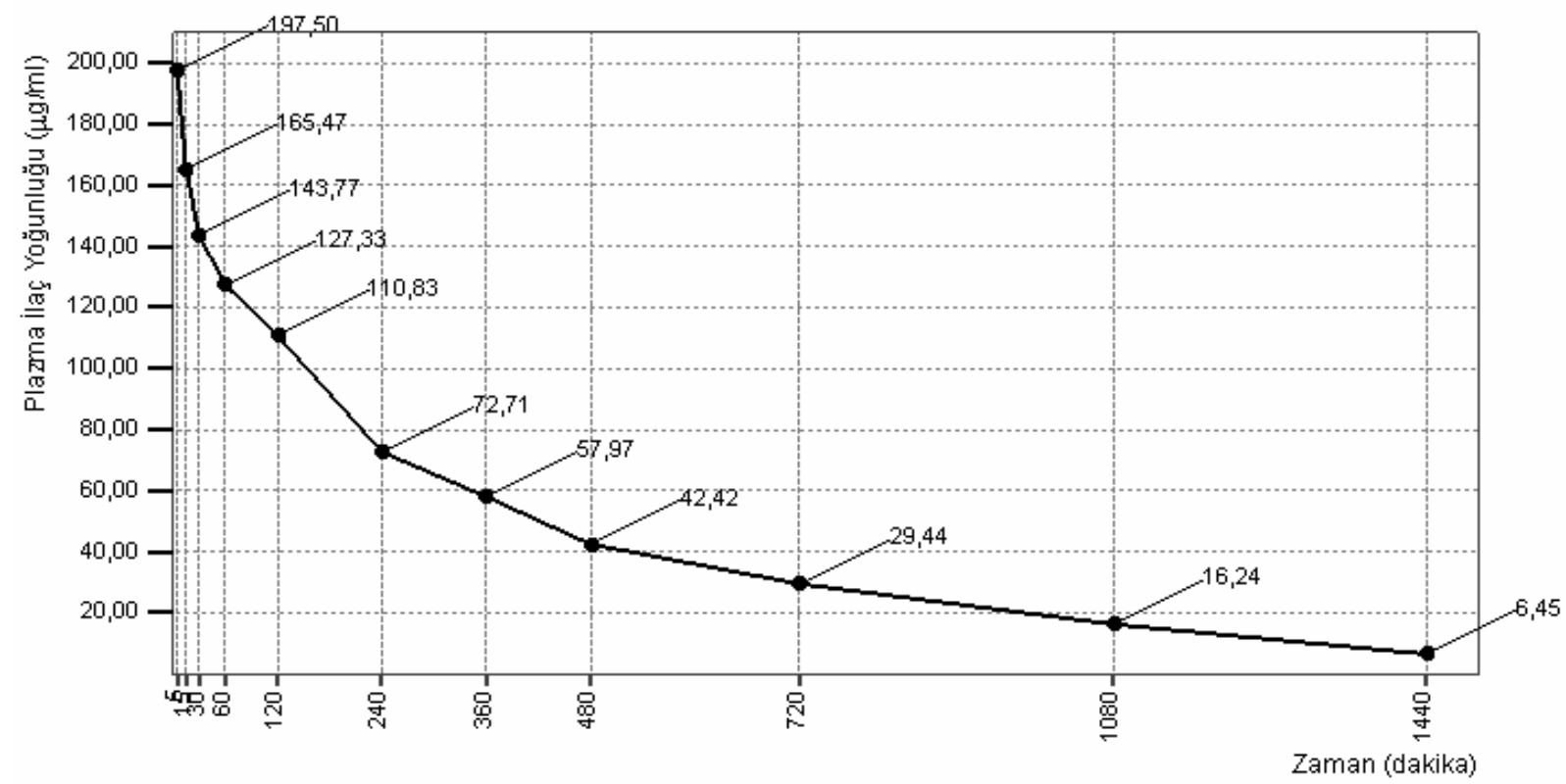

Şekil 1. Etlik piliçlere $100 \mathrm{mg} / \mathrm{kg}$ dozunda Dİ verilen sülfadiazine ait plazma ilaç yoğunluğu zaman eğrisi (Grup 1)

Figure 1: The time curve of plasma drug level of sulphadiazine of $100 \mathrm{mg} / \mathrm{kg}$ given intravenous to broilers (Group 1)

Tablo 2: Etlik piliçlere $100 \mathrm{mg} / \mathrm{kg}$ dozunda Dİ verilen sülfadiazine ait (Grup 1) farmakokinetik değişkenler (Ortalama \pm Standart hata).

Table 2: The pharmacokinetic variables of of sulphadiazine of $100 \mathrm{mg} / \mathrm{kg}$ given intravenous to broilers (Group 1) (Mean \pm Standard error).

\begin{tabular}{lcc}
\hline Farmakokinetik Değişkenler*** & Ortalama \pm Standart hata & En alt-en üst değerler \\
\hline $\mathrm{EAA}_{(0-24 \text { saat }}(\mu \mathrm{g} . \mathrm{saat} / \mathrm{ml})$ & $1065,35 \pm 13,89$ & $1031,88-1150,85$ \\
$\mathrm{~A}_{1}(\mu \mathrm{g} / \mathrm{ml})$ & $130,94 \pm 3,19$ & $113,64-149,94$ \\
$\mathrm{~A}_{2}(\mu \mathrm{g} / \mathrm{ml})$ & $80,60 \pm 3,92$ & $58,29-100,29$ \\
$\alpha\left(\mathrm{saat}^{-1}\right)$ & $2,05 \pm 0,02$ & $1,90-2,16$ \\
$\beta\left(\mathrm{saat}^{-1}\right)$ & $0,12 \pm 0,03$ & $0,09-0,15$ \\
$\mathrm{t}_{1 / 2 \alpha}(\mathrm{saat})$ & $0,33 \pm 0,02$ & $0,31-0,36$ \\
$\mathrm{t}_{1 / 2 \beta}(\mathrm{saat})$ & $5,59 \pm 0,07$ & $5,33-6,06$ \\
$\mathrm{MRT}_{(\mathrm{saat})}$ & $7,87 \pm 0,08$ & $7,50-8,40$ \\
$\mathrm{Vd}_{\mathrm{ss}}(\mathrm{L} / \mathrm{kg})$ & $0,72 \pm 0,04$ & $0,65-0,78$ \\
\hline
\end{tabular}

$\mathrm{n}=10$

***EAA, plazma ilaç yoğunluğu zaman eğrisi altındaki alan; $A_{1}$, merkezi bölmedeki ilaç miktarl; $A_{2}$, çevresel bölmedeki ilaç miktarı; $\alpha$, plazma ilaç yoğunluğu dağılma dönemi hız sabitesi; $\beta$, plazma ilaç yoğunluğu atılma dönemi hız sabitesi; $t_{1 / 2 \alpha,} \alpha$ dönemi yarl ömrü; $t_{1 / 2 \beta}, \beta$ dönemi yarı ömrü; MRT, ortalama kalış süres; $V_{\text {dss, }}$ ilacın kararlı durum dağılım hacmi $(13,14,16)$. 
Tablo 3: Çinkosuz yemle beslenen etlik piliçlerde kursağa $100 \mathrm{mg} / \mathrm{kg}$ dozunda verilen sülfadiazine ait (Grup 2) plazma ilaç yoğunluklarının aritmetik ortalaması (Ortalama \pm Standart hata).

Table 3: The arithmetic mean of plasma drug levels of sulphadiazine of $100 \mathrm{mg} / \mathrm{kg}$ given into gizzard of broilers fed zinc-free feed (Group 2)(Mean \pm Standard error).

\begin{tabular}{lcc}
\hline Zaman & Ortalama \pm Standart hata $(\mu \mathbf{g} / \mathbf{m l})$ & En alt-en üst değerler $(\boldsymbol{\mu g} / \mathbf{m l})$ \\
\hline 15. dakika & $47,17 \pm 0,84$ & $43,70-53,00$ \\
30. dakika & $52,60 \pm 0,55$ & $49,10-55,00$ \\
1. saat & $62,85 \pm 0,63$ & $59,20-65,90$ \\
2. saat & $66,46 \pm 0,49$ & $63,90-68,60$ \\
4. saat & $60,36 \pm 1,45$ & $51,60-65,40$ \\
6. saat & $55,79 \pm 0,73$ & $51,50-59,20$ \\
8. saat & $48,44 \pm 0,33$ & $46,80-49,90$ \\
12. saat & $35,69 \pm 0,41$ & $33,60-38,30$ \\
18. saat & $15,45 \pm 0,57$ & $11,90-16,60$ \\
24. saat & $9,11 \pm 0,35$ & $7,50-11,20$ \\
\hline
\end{tabular}

$\mathrm{n}=10$

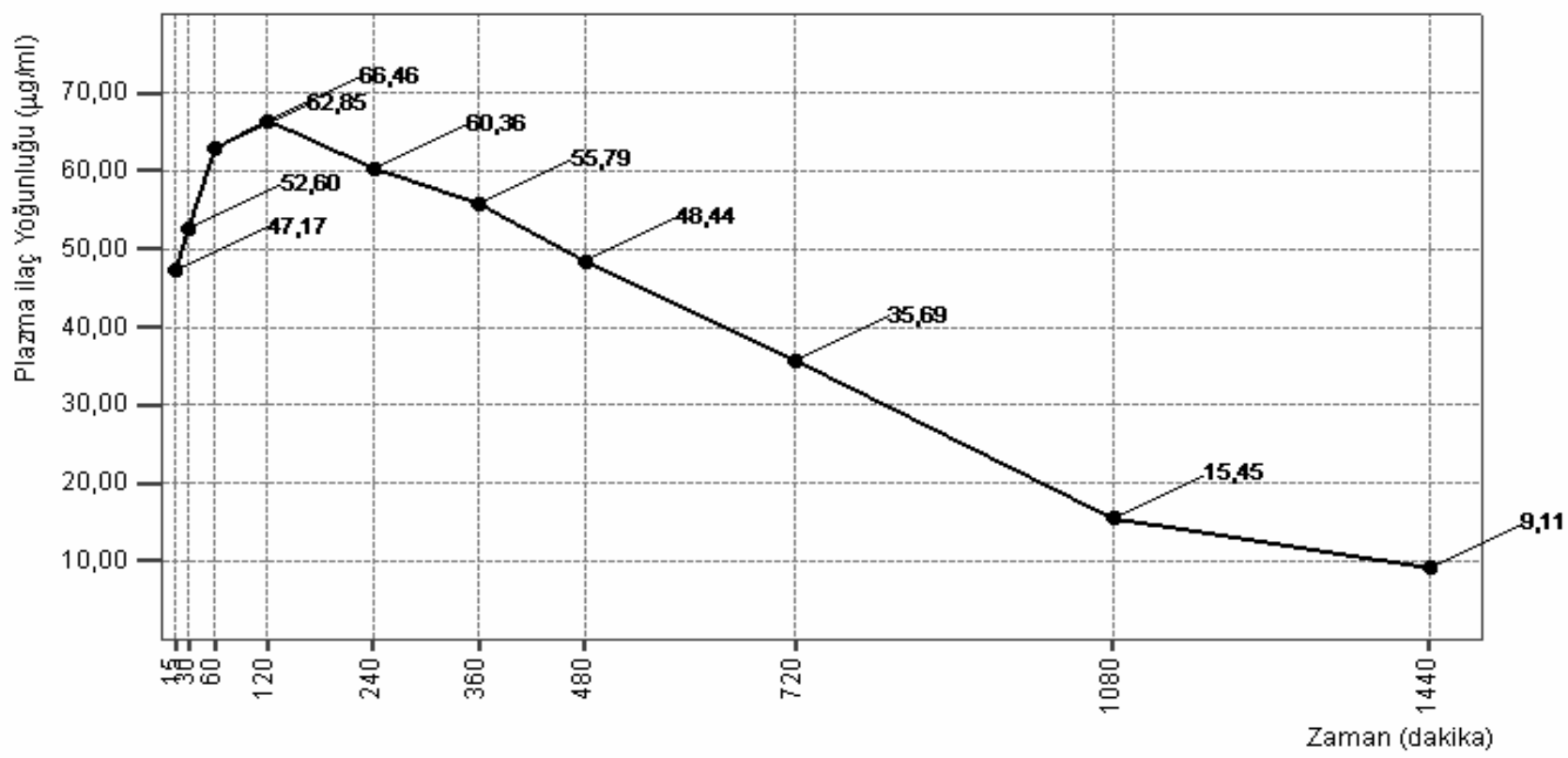

Şekil 2: Çinkosuz yemle beslenen etlik piliçlerde kursağa $100 \mathrm{mg} / \mathrm{kg}$ dozunda verilen sülfadiazine ait plazma ilaç yoğunluğu zaman eğrisi (Grup 2).

Figure 2: The time curve of plasma drug level of sulphadiazine of $100 \mathrm{mg} / \mathrm{kg}$ given into gizzard of broilers fed zincfree feed (Group 2). 
Tablo 4: Çinkosuz yemle beslenen etlik piliçlerde kursağa $100 \mathrm{mg} / \mathrm{kg}$ dozunda verilen sülfadiazine ait (Grup 2) farmakokinetik değişkenler (Ortalama \pm Standart hata).

Table 4:The pharmacokinetic variables of sulphadiazine of $100 \mathrm{mg} / \mathrm{kg}$ given into gizzard of broilers fed zinc-free feed (Group 2) )(Mean \pm Standard error).

\begin{tabular}{|c|c|c|}
\hline Farmakokinetik Değişkenler**** & Ortalama \pm Standart hata & En alt-en üst değerler \\
\hline $\operatorname{EAA}_{(0-24 \text { saat })}(\mu \mathrm{g}$. saat $/ \mathrm{ml})$ & $979,83 \pm 8,75$ & $945,50-1022,04$ \\
\hline $\mathrm{A}_{1}(\mu \mathrm{g} / \mathrm{ml})$ & $112,95 \pm 6,18$ & $87,24-147,00$ \\
\hline $\mathrm{A}_{2}(\mu \mathrm{g} / \mathrm{ml})$ & $-70,61 \pm 5,73$ & $-46,51-(-104,29)$ \\
\hline$\alpha\left(\right.$ saat $\left.^{-1}\right)$ & $1,76 \pm 0,05$ & $1,49-1,99$ \\
\hline$\beta\left(\right.$ saat $\left.^{-1}\right)$ & $0,10 \pm 0,03$ & $0,07-0,14$ \\
\hline $\mathrm{t}_{1 / 2 \alpha}$ (saat) & $0,39 \pm 0,02$ & $0,36-0,42$ \\
\hline $\mathrm{t}_{1 / 2 \beta}$ (saat) & $6,57 \pm 0,19$ & $5,78-7,74$ \\
\hline MRT (saat) & $10,55 \pm 0,18$ & $10,09-11,87$ \\
\hline $\mathrm{C}_{\text {doruk }}(\mu \mathrm{g} / \mathrm{ml})$ & $66,46 \pm 0,49$ & $63,90-68,60$ \\
\hline$t_{\text {doruk }}($ saat $)$ & 2 & - \\
\hline $\mathrm{F}(\%)$ & 91,97 & - \\
\hline
\end{tabular}

Sülfadiazinin, etlik piliçlerde Dİ ve kursağa $100 \mathrm{mg} / \mathrm{kg}$ dozunda verilmesi hâlinde (Grup 1 ve 2) elde edilen farmakokinetik değişkenlerden $\mathrm{t}_{1 / 2 \beta}$ (Dİ 5,59 $\pm 0,07$ saat; kursak 6,57 $\pm 0,19$ saat) değeri yönünden aralarında istatistik açıdan önemli $(\mathrm{p}<0,05)$ fark bulunduğu görülmüş̧ür.

Çalışma gruplarından Grup 3'e ait plazma ilaç yoğunluklarının aritmetik ortalamaları Tablo 5 'te, plazma ilaç yoğunluğu zaman eğrisi Şekil 3'te, farmakokinetik değişkenler Tablo 6'da; Grup 4'e ait plazma ilaç yoğunluklarının aritmetik ortalamaları Tablo 7'de, plazma ilaç yoğunluğu zaman eğrisi Şekil 4'te, farmakokinetik değişkenler ise Tablo 8'de verilmiştir. 
Tablo 5: Çinkolu yemle beslenen etlik piliçlerde kursağa $100 \mathrm{mg} / \mathrm{kg}$ dozunda verilen sülfadiazine ait (Grup 3) plazma ilaç yoğunluklarının aritmetik ortalaması (Ortalama \pm Standart hata).

Table 5: The arithmetic mean of plasma drug levels of sulphadiazine of $100 \mathrm{mg} / \mathrm{kg}$ given into gizzard of broilers fed zinc-added feed (Group 3) (Mean \pm Standard error).

\begin{tabular}{lcc}
\hline Zaman & Ortalama \pm Standart hata $(\mu \mathbf{g} / \mathbf{m l})$ & En alt-en üst değerler $(\boldsymbol{\mu g} / \mathbf{m l})$ \\
\hline 15. dakika & $16,79 \pm 0,75$ & $12,10-19,70$ \\
30. dakika & $39,72 \pm 1,39$ & $34,40-44,50$ \\
1. saat & $49,45 \pm 1,59$ & $43,70-57,70$ \\
2. saat & $58,04 \pm 1,63$ & $51,90-65,40$ \\
4. saat & $44,97 \pm 1,96$ & $35,20-52,20$ \\
6. saat & $34,65 \pm 1,78$ & $29,00-42,90$ \\
8. saat & $24,24 \pm 0,92$ & $20,50-28,20$ \\
12. saat & $19,29 \pm 0,63$ & $17,40-22,50$ \\
18. saat & $13,23 \pm 0,30$ & $11,90-15,00$ \\
24. saat & $6,58 \pm 0,13$ & $5,70-7,30$ \\
\hline
\end{tabular}

$\mathrm{n}=10$

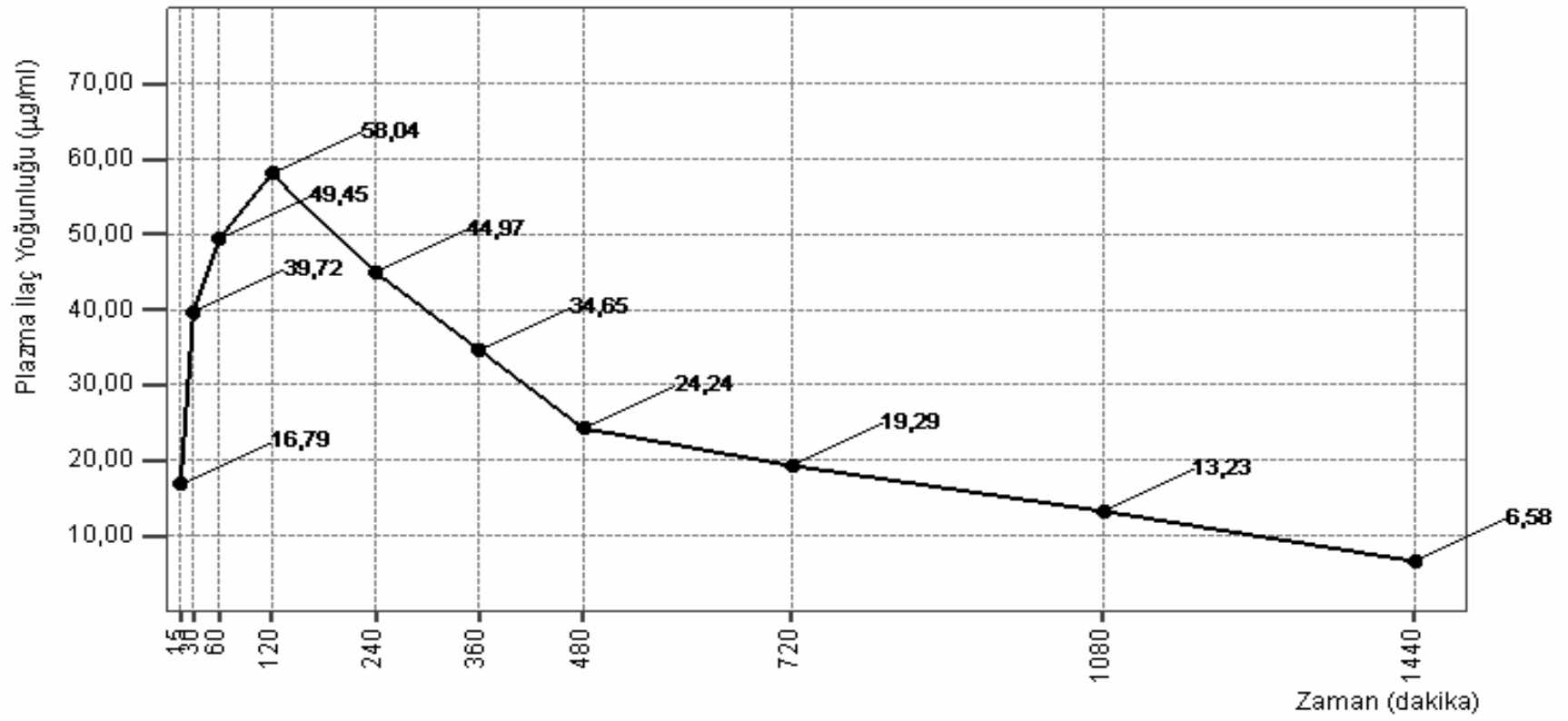

Şekil 3: Çinkolu yemle beslenen etlik piliçlerde kursağa $100 \mathrm{mg} / \mathrm{kg}$ dozunda verilen sülfadiazine ait plazma ilaç yoğunluğu zaman eğrisi (Grup 3).

Figure 3: The time curve of plasma drug level of sulphadiazine of $100 \mathrm{mg} / \mathrm{kg}$ given into gizzard of broilers fed zincfree feed (Group 3). 
Tablo 6: Çinkolu yemle beslenen etlik piliçlerde kursağa $100 \mathrm{mg} / \mathrm{kg}$ dozunda verilen sülfadiazine ait (Grup 3) farmakokinetik değişkenler (Ortalama \pm Standart hata).

Table 6: The pharmacokinetic variables of sulphadiazine of $100 \mathrm{mg} / \mathrm{kg}$ given into gizzard of broilers fed zinc-added feed (Group 3) )(Mean \pm Standard error).

\begin{tabular}{lcc}
\hline Farmakokinetik Değişkenler**** & Ortalama \pm Standart hata & En alt-en üst değerler \\
\hline $\mathrm{EAA}_{(0-24 \text { saat })}(\mu \mathrm{g} . \mathrm{saat} / \mathrm{ml})$ & $683,33 \pm 11,12$ & $630,03-743,90$ \\
$\mathrm{~A}_{1}(\mu \mathrm{g} / \mathrm{ml})$ & $60,78 \pm 2,04$ & $51,56-69,24$ \\
$\mathrm{~A}_{2}(\mu \mathrm{g} / \mathrm{ml})$ & $-96,62 \pm 6,35$ & $-60,30-(133,62)$ \\
$\alpha\left(\mathrm{saat}^{-1}\right)$ & $1,52 \pm 0,03$ & $1,40-1,74$ \\
$\beta\left(\mathrm{saat}^{-1}\right)$ & $0,09 \pm 0,02$ & $0,07-0,13$ \\
$\mathrm{t}_{1 / 2 \alpha}(\mathrm{saat})$ & $0,45 \pm 0,03$ & $0,40-0,48$ \\
$\mathrm{t}_{1 / 2 \beta}(\mathrm{saat})$ & $7,60 \pm 0,17$ & $6,62-8,22$ \\
$\mathrm{MRT}(\mathrm{saat})$ & $11,49 \pm 0,24$ & $10,04-12,39$ \\
$\mathrm{C}_{\text {doruk }}(\mu \mathrm{g} / \mathrm{ml})$ & $58,04 \pm 1,63$ & $51,90-65,40$ \\
$\mathrm{t}_{\text {doruk }}(\mathrm{saat})$ & 2 & - \\
$\mathrm{F}(\%)$ & 64,14 & - \\
\hline
\end{tabular}

$\mathrm{n}=10$

***EAA, plazma ilaç yoğunluğu zaman ĕgrisi altındaki alan; $A_{1}$, merkezi bölmedeki ilaç miktarl; $A_{2}$, çevresel bölmedeki ilaç miktarı; $\alpha$, plazma ilaç yoğunluğu dă̆lma dönemi hız sabitesi; $\beta$, plazma ilaç yoğunluğu atılma dönemi hız sabitesi; $t_{1 / 2}, \alpha$ dönemi yarı ömrü; $t_{1 / 2 \beta}, \beta$ dönemi yarı ömrü; MRT,

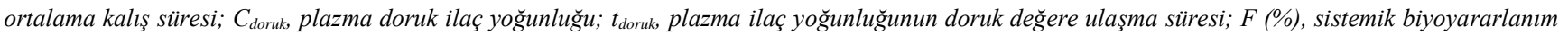
$(13,14,16)$.

Sülfadiazin, çinkosuz ve 200 ppm çinkolu yemle beslenen etlik piliçlerde doğrudan kursağa 100 $\mathrm{mg} / \mathrm{kg}$ miktarında verildiğinde (Grup 2 ve 3) elde edilen farmakokinetik değişkenler arasında istatistik açıdan önemli fark ( $\mathrm{p}>0,05)$ görülmemiştir.

Tablo 7: Çinkolu yemle beslenen etlik piliçlere içme suyu ile $100 \mathrm{mg} / \mathrm{kg}$ dozunda verilen sülfadiazine ait (Grup 4) plazma ilaç yoğunluklarının aritmetik ortalaması (Ortalama \pm Standart hata).

Table 7: The arithmetic mean of plasma drug levels of sulphadiazine of $100 \mathrm{mg} / \mathrm{kg}$ given by drinking water to broilers fed zinc-added feed (Group 4)(Mean \pm Standard error).

\begin{tabular}{lcc}
\hline Zaman & Ortalama \pm Standart hata $(\boldsymbol{\mu g} / \mathbf{m l})$ & En alt-en üst değerler $(\boldsymbol{\mu g} / \mathbf{m l})$ \\
\hline 15. dakika & $21,98 \pm 1,11$ & $18,30-27,60$ \\
30. dakika & $39,47 \pm 0,81$ & $34,40-42,40$ \\
1. saat & $45,45 \pm 1,77$ & $39,50-55,50$ \\
2. saat & $62,64 \pm 2,13$ & $50,40-68,50$ \\
4. saat & $51,04 \pm 0,82$ & $47,30-54,80$ \\
6. saat & $45,66 \pm 1,36$ & $38,00-53,00$ \\
8. saat & $29,14 \pm 1,36$ & $24,00-36,70$ \\
12. saat & $14,68 \pm 0,39$ & $12,70-16,60$ \\
18. saat & $9,10 \pm 0,39$ & $7,30-11,20$ \\
24. saat & $6,19 \pm 0,14$ & $5,30-6,80$ \\
\hline
\end{tabular}

$\mathrm{n}=10$ 


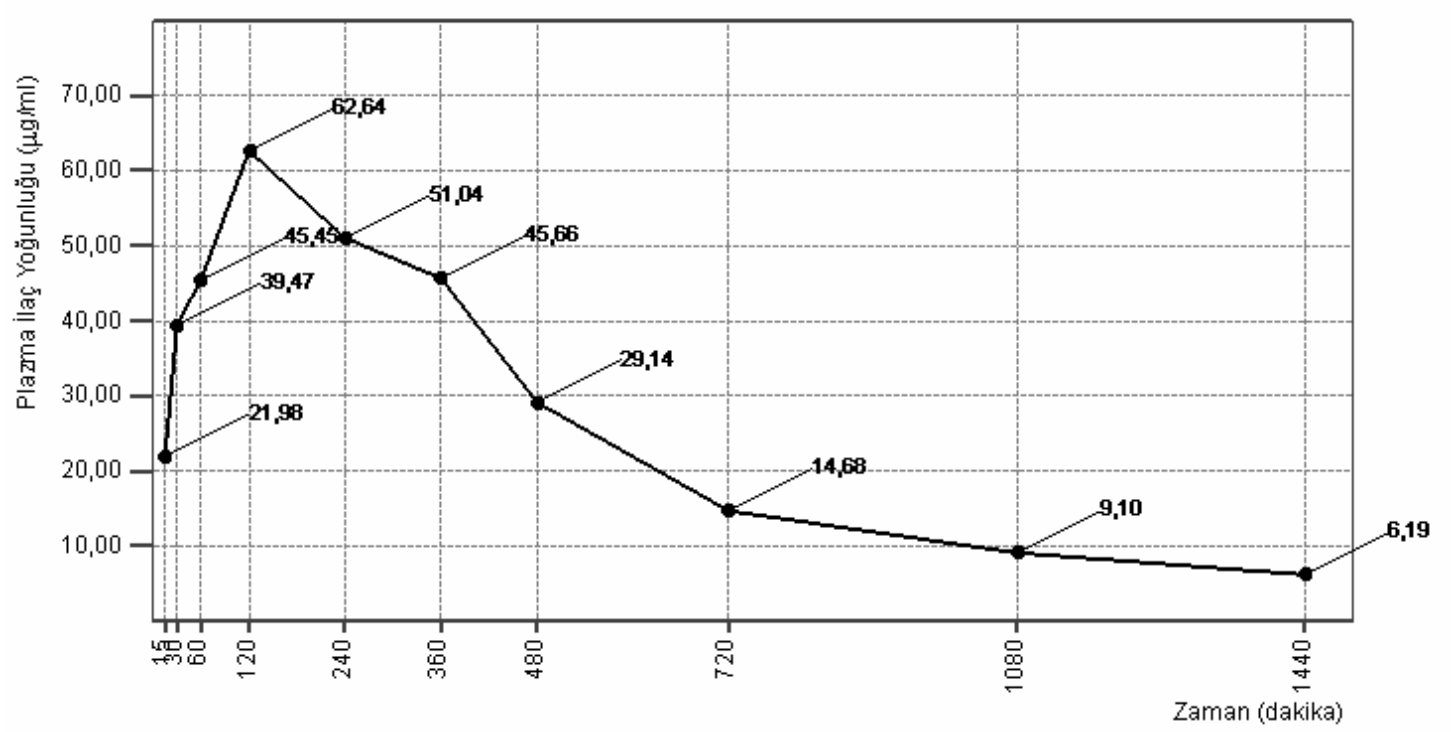

Şekil 4: Çinkolu yemle beslenen etlik piliçlere içme suyu ile $100 \mathrm{mg} / \mathrm{kg}$ dozunda verilen sülfadiazine ait plazma ilaç yoğunluğu zaman eğrisi (Grup 4).

Figure 4: The time curve of plasma drug level of sulphadiazine of $100 \mathrm{mg} / \mathrm{kg}$ given by drinking water to broilers fed zinc-added feed (Group 4).

Tablo 8: Çinkolu yemle beslenen etlik piliçlere içme suyu ile $100 \mathrm{mg} / \mathrm{kg}$ dozunda verilen sülfadiazine ait (Grup 4) farmakokinetik değişkenler (Ortalama \pm Standart hata).

Table 8: The pharmacokinetic variables of sulphadiazine of $100 \mathrm{mg} / \mathrm{kg}$ given by drinking water to broilers fed zincadded feed (Group 4) ) (Mean \pm Standard error).

\begin{tabular}{lcc}
\hline Farmakokinetik Değişkenler**** & Ortalama \pm Standart hata & En alt-en üst değerler \\
\hline EAA $_{(0-24 \text { saat })}(\mu \mathrm{g} . \mathrm{saat} / \mathrm{ml})$ & $647,86 \pm 4,77$ & $621,50-671,64$ \\
$\mathrm{~A}_{1}(\mu \mathrm{g} / \mathrm{ml})$ & $75,91 \pm 0,99$ & $71,59-81,20$ \\
$\mathrm{~A}_{2}(\mu \mathrm{g} / \mathrm{ml})$ & $-67,61 \pm 2,27$ & $-57,50-(81,18)$ \\
$\alpha\left(\mathrm{saat}^{-1}\right)$ & $1,87 \pm 0,02$ & $1,75-2,01$ \\
$\beta$ (saat $\left.^{-1}\right)$ & $0,11 \pm 0,02$ & $0,09-0,14$ \\
$\mathrm{t}_{1 / 2 \alpha}(\mathrm{saat})$ & $0,37 \pm 0,04$ & $0,32-0,41$ \\
$\mathrm{t}_{1 / 2 \beta}$ (saat) & $6,16 \pm 0,08$ & $5,73-6,58$ \\
$\mathrm{MRT}(\mathrm{saat})$ & $9,62 \pm 0,11$ & $9,18-10,22$ \\
$\mathrm{C}_{\text {doruk }}(\mu \mathrm{g} / \mathrm{ml})$ & $62,64 \pm 2,13$ & $50,40-68,50$ \\
$\mathrm{t}_{\text {doruk }}(\mathrm{saat})$ & 2 & - \\
$\mathrm{F}(\%)$ & 60,81 & - \\
\hline
\end{tabular}

***EAA, plazma ilaç yoğunluğu zaman ĕgrisi altındaki alan; $A_{1}$, merkezi bölmedeki ilaç miktarl; $A_{2}$, çevresel bölmedeki ilaç miktarl; $\alpha$, plazma ilaç yoğunluğu dă̆llma dönemi hız sabitesi; $\beta$, plazma ilaç yoğunluğu atılma dönemi hız sabitesi; $t_{1 / 2 \alpha}, \alpha$ dönemi yarı ömrü; $t_{1 / 2 \beta} \beta$ dönemi yarı ömrü; MRT,

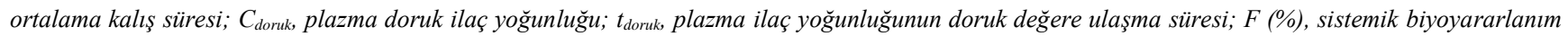
$(13,14,16)$.

Çinkolu yemle beslenen ve $100 \mathrm{mg} / \mathrm{kg}$ miktarında kursağa ilaç verilen grup (Grup 3) ile yine çinkolu yemle beslenen, ancak ilacın aynı dozda içme suyuna katılarak verildiği gruba (Grup 4) ait farmakokinetik değişkenlerden sirasiyla EAA $(683,33 \pm 11,12 \mu \mathrm{g}$.saat $/ \mathrm{ml}$ ve $647,86 \pm 4,77 \mu \mathrm{g} . \mathrm{saat} / \mathrm{ml}), \mathrm{A}_{1}(60,78 \pm 2,04 \mu \mathrm{g} / \mathrm{ml}$ ve 75,91 $\pm 0,99 \mu \mathrm{g} / \mathrm{ml})$, $\mathrm{t}_{1 / 2 \beta}(7,60 \pm 0,17$ saat ve6,16 $\pm 0,08$ saat $)$ ve MRT $(11,49 \pm 0,24$ saat ve 9,62 $\pm 0,11$ saat $)$ arasında istatistik açıdan önemli $(p<0,05)$ farkların bulunduğu görülmüsstür. 


\section{Tartışma ve Sonuç}

Sülfadiazinin etlik piliçlere $100 \mathrm{mg} / \mathrm{kg}$ miktarında Dİ verilmesinden sonra, plazma ilaç yoğunluğu ilk birinci saatte hızla düşmüş olup bu durum dağılım dönemi yarı ömrünün $\left(\mathrm{t}_{1 / 2 \alpha}=0,33 \pm 0,02\right.$ saat) kısa süreli olmasından da görülmektedir.

Sülfadiazin, Dİ ve kursağa $100 \mathrm{mg} / \mathrm{kg}$ dozunda verildiğinde vücutta hızla (Dİ $\mathrm{t}_{1 / 2 \alpha}=0,33 \pm 0,02$ saat; kursak $\mathrm{t}_{1 / 2 \alpha}=0,39 \pm 0,02$ saat) dağılmıştır. İlacın atılma dönemi yarı ömrü $\left(\mathrm{t}_{1 / 2 \beta}\right)$ kursağa verilme durumunda 6,57 $\pm 0,19$ saat iken, Dİ olarak verilmesi durumunda atılma dönemi yarı ömrü $\left(t_{1 / 2 \beta}\right) 5,59 \pm 0,07$ saat olarak gerçekleşmiştir. Her iki gruba ait $\mathrm{t}_{1 / 2 \alpha}$ ve $\mathrm{t}_{1 / 2 \beta}$ değerlerinin birbirine yakın olduğu görülmektedir.

Sülfadiazin, kursağa $100 \mathrm{mg} / \mathrm{kg}$ dozunda verildiğinde 2 saatte $\left(\mathrm{t}_{\text {doruk }}\right)$ plazmada doruk yoğunluğa $\left(\mathrm{C}_{\text {doruk }}=66,46\right.$ $\pm 0,49 \mu \mathrm{g} / \mathrm{ml}$ ) ulaşmıştır; Şekil 2'de de görüldüğü gibi yaklaşık 8. saate kadar (8. saatte 48,44 $\pm 0,33 \mu \mathrm{g} / \mathrm{ml}$ ) sülfadiazinin en küçük etkili kan yoğunluğu olan $40 \mu \mathrm{g} / \mathrm{ml}$ 'nin $(11,15)$ üzerinde kalmıştır. Yine bu etkili yoğunluk Dİ uygulamada da 8 . saate kadar (8. saatte $42,42 \pm 1,69 \mu \mathrm{g} / \mathrm{ml}$ ) sürmüştür.

Sülfadiazinin kursağa $100 \mathrm{mg} / \mathrm{kg}$ miktarında verilmesini takiben plazma doruk yoğunluğa ulaşma süresi $\left(t_{\text {doruk }}=2\right.$ saat $)$ ile etkili plazma yoğunluğu ve bu etkili yoğunluğun devam etme süresi, yapılan benzer araştırmalara uyum göstermektedir $(17,19)$. Ancak, bu araştırmada aynı dozda verilen sülfadiazinin yine aynı sürede ulaştığı doruk plazma ilaç yoğunluğu $\left(\mathrm{C}_{\text {doruk }}=66,46 \pm 0,49 \mu \mathrm{g} / \mathrm{ml}\right)$, Reddy ve ark (19)'nın Leghorn ırkı 2-2,5 yaşındaki yumurtacı tavuklarda yaptıkları çalışmada bulunan değere $\left(\mathrm{C}_{\text {doruk }}=148,25 \mu \mathrm{g} / \mathrm{ml}\right)$ göre daha düşük olarak bulunmuştur. Bu durum, çalışmada kullanılan hayvanların ırk, yaş ve beslenme farklılıklarından kaynaklanmış olabilir.

Yumurtacı tavuklara ağızdan $100 \mathrm{mg} / \mathrm{kg}$ dozunda trimetoprim ile kombine sülfadiazin verilerek yapılan bir çalışmada da (24) plazma doruk yoğunluğa ulaşma süresi 2,46 saat, plazma ilaç doruk yoğunluğu ise $86,45 \mu \mathrm{g} / \mathrm{ml}$ olarak belirlenmiştir. $\mathrm{Bu}$ farklılık ise, sülfadiazinin kombine olarak verilmesinden veya hayvanlar arasındaki rrk farklılığından kaynaklanmış olabilir.

Chandra ve ark (7) Beç tavuklarında yaptıkları bir çalışmada $200 \mathrm{mg} / \mathrm{kg}$ miktarında ve ağızdan verdikleri sülfadiazinin plazma doruk yoğunluğa ulaşma süresini 3 saat, plazma doruk yoğunluğunu ise 64,29 $\pm 0,60 \mu \mathrm{g} / \mathrm{ml}$ olarak belirlemişlerdir. İlacın plazma doruk yoğunluğa ulaşma süresi bu araştırmada bulunan değerden 1 saat kadar bir yükseklik gösterse de plazma ilaç doruk yoğunluğu değerlerinin birbirine çok yakın olduğu görülmektedir. Bunun yan 1sıra, ilacın plazma doruk değere ulaşma süresindeki değişiklik, Beç tavuğu ile etlik piliçler arasındaki farklılıklardan ileri gelebilir.

İlacın dağılma dönemi yarı ömrü ( $\mathrm{t}_{1 / 2 \alpha}$ ), Dİ $100 \mathrm{mg} / \mathrm{kg}$ miktarında uygulandığında $0,33 \pm 0,02$ saat, aynı dozda kursağa verilmesi hâlinde $0,39 \pm 0,02$ saat olarak bulunmuştur. Bu değer, yumurtacı tavuklara aynı dozda ilaç verilerek yapılan bir çalışmada (19), ilacın Dİ verilmesi hâlinde 0,301 saat, ağızdan verilmesi durumunda ise 0,461 saat olarak belirlenmiştir. $\mathrm{Bu}$ araştırmada bulunan $\mathrm{t}_{1 / 2 \alpha}$ değerleri ile araştırıcıların (19) bulduğu değerler birbirine yakındır.

Sülfadiazinin etlik piliçlere $100 \mathrm{mg} / \mathrm{kg}$ dozunda Dİ verilmesiyle $\alpha=2,05 \pm 0,02$ saat $^{-1}, \beta=0,12 \pm 0,03$ saat $^{-1}$ olarak gerçekleşmiştir. Reddy ve ark (19) 1,5-2 yaşındaki yumurtacı tavuklara $100 \mathrm{mg} / \mathrm{kg}$ sülfadiazini Dİ vererek yaptıkları çalışmada $\alpha$ değerini 2,30 saat $^{-1}, \beta$ değerini ise 0,303 saat $^{-1}$ olarak bulmuşlardır. $\alpha$ değeri bu araştırmadaki değere yakın bir değer olmakla birlikte, $\beta$ değeri bu çalışmada daha küçük olarak belirlenmiştir. Bu durum, etlik piliçlerde sülfadiazinin atılmasının yumurtacı tavuklara göre daha yavaş olduğunu göstermektedir.

Sülfadiazinin $100 \mathrm{mg} / \mathrm{kg}$ miktarında etlik piliçlerde kursağa verilmesi ile $\alpha=1,76 \pm 0,05$ saat $^{-1}, \beta$ ise $0,10 \pm$ 0,03 saat $^{-1}$ olarak belirlenmiştir. Reddy ve ark (19) yumurtacı tavuklara ağızdan $100 \mathrm{mg} / \mathrm{kg}$ miktarında sülfadiazin vererek yaptıkları çalışmada $\alpha$ değerini 1,504 saat $^{-1}, \beta$ değerini ise 0,154 saat $^{-1}$ olarak bulmuşlardır. Her iki çalışmada da bulunan değerlerin birbirine yakın olduğu görülmektedir.

$\mathrm{Bu}$ araştırmada, sülfadiazinin $100 \mathrm{mg} / \mathrm{kg}$ dozunda Dİ verilmesi hâlinde atılma dönemi yarı ömrü $\left(\mathrm{t}_{1 / 2 \beta}\right) 5,59 \pm$ 0,07 saat, aynı dozda kursağa verilmesi hâlinde ise 6,57 $\pm 0,19$ saat olarak bulunmuştur. Her iki uygulamada da elde edilen değerler birbirine yakındır. 
Elde edilen bu veriler, sülfadiazinin etlik piliçlere $100 \mathrm{mg} / \mathrm{kg}$ dozunda 8 saat arayla verilmesi durumunda etkili plazma yoğunluğunu sürdürebileceğini ortaya koymaktadır.

Sülfadiazinin etlik piliçlere $100 \mathrm{mg} / \mathrm{kg}$ dozunda Dİ verilmesiyle EAA =1065,35 $\pm 13,89 \mu \mathrm{g}$.saat/ml; kursağa verilmesiyle de EAA $=979,83 \pm 8,75 \mu \mathrm{g}$.saat $/ \mathrm{ml}$ olarak bulunmuştur. Her iki değer de birbirine yakın olup bu durum ilacın biyoyayarlanımının yüksek (\% 91,97) olarak gerçekleşmesinin bir sonucudur. Reddy ve ark (19) yine aynı dozda ağızdan ilaç vererek yumurtacı tavuklarda EAA'yı bu değere yakın bir değer $(\mathrm{EAA}=881,63 \mu \mathrm{g}$.saat/ml) olarak belirlemişlerdir.

İlacın, 200 ppm çinkolu ve çinkosuz yemle beslenen etlik piliçlerde kursağa $100 \mathrm{mg} / \mathrm{kg}$ dozunda verilmesi sonucunda yapılan hesaplamalarda sistemik biyoyararlanımları (F) yönünden de aralarında önemli farkın bulunduğu görülmüştür. Çinkosuz yemle beslenen ve kursağa sülfadiazin verilen grupta (Grup 2) biyoyararlanım hayli yüksek (F= \% 91,97) iken, 200 ppm çinkolu yemle beslenen ve yine kursağa ilaç verilen grupta (Grup 3) bu değer \% 64,14 olarak bulunmuştur. Çinkosuz yemle beslenen grupta (Grup 2) ilacın biyoyararlanımı ( $\mathrm{F}=\%$ 91,97), Reddy ve ark (19) tarafindan bildirilen biyoyararlanım değeri $(\mathrm{F}=\%$ 91,66) ile benzerlik göstermektedir.

Bazı araştırıcılar (17) ise trimetoprim ile birlikte $100 \mathrm{mg} / \mathrm{kg}$ miktarında verilen sülfadiazinin etlik piliçlerdeki biyoyararlanımını yaklaşık \% 100 olarak belirtmişlerdir. Bununla birlikte, yine trimetoprimle birlikte etlik piliçlere ağızdan 33,34 mg/kg miktarında verilen sülfadiazinin biyoyararlanımını Baert ve ark (6) da yaklaşık \% 80 olarak belirlemişlerdir. Diğer yandan, Abu-Basha ve ark (1) da deve kuşlarına, trimetoprimle birlikte kas içi ve ağız yoluyla verdikleri $25 \mathrm{mg} / \mathrm{kg}$ dozundaki sülfadiazinnin biyoyararlanımını sırasıyla \% 95,41 ve \% 86,20 olarak tespit etmişlerdir.

Dagorn ve ark (8) etlik piliçlere, trimetoprim ile kombine olarak $20 \mathrm{mg} / \mathrm{kg} /$ gün dozunda 96 saat süreyle ve içme suyuna katarak verdikleri sülfadiazinin biyoyararlanımını $\% 99,77$ olarak belirlemişlerdir.

$\mathrm{Bu}$ çalışmada yeminde çinko bulunmayan gruptaki (Grup 2) biyorarlanım değeri ile kaynaklarda belirtilen biyoyararlanım değerleri $(6,8,17,19)$, sülfadiazinin kanatlılardaki biyoyararlanımının hem birbirine yakın hem de çok yüksek olduğunu göstermektedir.

Grup 2, 3 ve 4'te ilacın plazma doruk düzeye ulaşma süresi aynıdır ( $t_{\text {doruk }}=2$ saat $)$. Ancak, yeminde çinko bulunmayan grupta (Grup 2) ilacın etkili plazma yoğunluğuna ulaşması 15. dakikada olmuş ve 8. saate kadar devam etmiştir. Çinkolu yemle beslenen Grup 3 ve 4 'te ise, ilaç etkili plazma yoğunluğuna yaklaşı olarak verilmesinden bir saat sonra ulaşmış, ancak bu etkili yoğunluk Grup 3'te 4. saate, Grup 4'te ise 6. saate kadar devam etmiştir. Bu sonuçlar, yeminde çinko bulunan gruplarda (Grup 3 ve 4) sülfadiazinin emiliminin çinko tarafından sınırlandırıldığına işaret eden önemli bulgulardır.

İlacın dağılma dönemi yarı ömrü ( $\left.\mathrm{t}_{1 / 2 \alpha}\right)$ çinkosuz yemle beslenen ve kursağa ilaç uygulanan grupta (Grup 2) $0,39 \pm 0,02$ saat; 200 ppm çinkolu yemle beslenen ve kursağa ilaç verilen grupta (Grup 3) ise 0,45 \pm 0,03 saat olarak belirlenmiştir. Her iki grupta da $t_{1 / 2 \alpha}$ değerleri birbirine yakın olarak bulunmuştur. $\mathrm{Bu}$ durum, çinkolu ve çinkosuz yemle beslenme durumuna göre sülfadiazinin dağılımının birbirine yakın olduğunu ifade etmektedir.

EAA çinkosuz yemle beslenen ve kursağa ilaç verilen grupta (Grup 2) $979,83 \pm 8,75 \mu \mathrm{g}$. saat $/ \mathrm{ml}$, çinkolu yemle beslenen ve yine kursağa ilaç verilen grupta (Grup 3) $\mathrm{EAA}=683,33 \pm 11,12 \mu \mathrm{g}$.saat $/ \mathrm{ml}$ olarak bulunmuştur. Çinkolu yemle beslenen ve ilacın içme suyu ile verildiği grupta (Grup 4) ise EAA=647,83 $\pm 4,77 \mu \mathrm{g}$.saat/ml olarak belirlenmiştir. Yapılan hesaplamalarda F değeri çinkosuz yemle beslenen ve kursağa ilaç verilen grupta (Grup 2) \% 91,97 iken, çinkolu yemle beslenen ve kursağa ilaç verilen grupta (Grup 3) \% 64,14 olmuş, yine çinkolu yemle beslenen, ancak ilacın içme suyu ile verildiği grupta (Grup 4) ise bu değer \% 60,81 olarak bulunmuştur. Yemle 200 ppm çinko alan gruplardaki (Grup 3 ve 4) EAA'ların düşüklüğü, bu gruplarda ilacın biyoyararlanımının da düşük olması şeklinde kendini göstermiştir.

$\mathrm{Bu}$ sonuçlar, çinkolu yemle beslenen etlik piliçlerin, çinkosuz yemle beslenenlere göre sülfadiazinden daha az oranda yararlandığına delalet etmektedir.

Çinkosuz yemle beslenen ve kursağa ilaç verilen grup (Grup 2) ile çinkolu yemle beslenen ve kursağa ilaç verilen grup (Grup 3) arasında ilacın biyoyararlanımı (F) yönünden \% 30,26'lık bir kayıp var iken, bu kayıp çinkolu yemle beslenen ve ilacın içme suyu ile uygulandığı grupta (Grup 4) ise \% 33,89 olarak gerçekleşmiştir. Elde edilen bu değerler, sülfadiazinin emiliminin çinko tarafindan engellendiğini ve her iki grupta da (Grup 3 ve 4) ilacın 
biyoyararlanımının \% 30’un üzerinde düştüğünü göstermektedir. Bu bağlanmanın bir neticesi olarak çinkonun da emiliminin sınırlanabileceği ve hayvanların çinkodan yeteri kadar yararlanamayacağı düşüncesi akla gelmektedir.

Araştırma sonuçları, sülfadiazinin etlik piliçlerde sindirim kanalından emilme oranının hayli yüksek olduğunu,

ancak çinko ile birlikte verilmesi hâlinde biyoyararlanımın düştüğünü göstermiştir. Elde edilen bulgulardan, sülfadiazinin kanatlılarda kullanılması durumunda hem minerallerin emiliminin bozulabileceği hem de sülfadiazinin biyoyayarlanımının düşebileceği sonucuna varılmıştır.

\section{Kaynaklar}

1. Abu-Basha EA, Gehring R, Hantash TM, Al-Shunnaq AF, Idkaidek NM (2009): Pharmacokinetics and bioavailability of sulfadiazine and trimethoprim following intravenous, intramuscular and oral administration in ostriches (Struthio camelus). J Vet Pharmacol Ther, 32, 258-263.

2. Aksoy T (1991): Tavuk Yetiştiriciliği. Şahin Matbaası, Ankara.

3. Arda M, Minbay A, Aydın N, Akay Ö, İzgür M (1994): Kanatlı Hayvan Hastalıkları. Medisan Yayınevi, Ankara.

4. Atef M, Youssef SAH, Ramadan A, Afifi NA, Mutty AA (1994): Interaction between lead toxicity and some sulphonamides in rabbits: effect on certain blood constituent and serum enzymes. DTW, 101, 187-190.

5. Baenziger NC, Modak SL, Fox CL (1983): Diamminebis (2-sulfanilamido-pyrimidinato) zinc (ll), [Zn (C1O H9 N4 O2 S )2 (NH3)2 ]. Acta Cryst, 39, 1620-1623.

6. Baert K, De Baere S, Croubels S, De Backer P (2003): Pharmacokinetics and oral bioavailability of sulfadiazine and trimethoprim in broiler chickens. Vet Res Commun, 27, 301-309.

7. Chandra S, Gupta PK, Gupta S, Vijjan VK (1997): Pharmacokinetics of sulphadiazine in guinea-fowl following single oral administration. Indian J Poult, 32, 173-175.

8. Dagorn M, Moulin G, Laurentie M, Delmas JM (1991): Plasma and pharmacokinetics of trimethoprim and sulphadiazine combinations administered to broilers. Acta Vet Scand Suppl, 87, 273-275.

9. Gezer S (1993): Hematoloji. Etam AŞ Web-Ofset, Eskişehir.

10.Haagsma N, Dielemen B, Gortemaker BGM (1984): A rapid thin-layer chromatographic screening method for five sulfonamides in animal tissues. Vet Quart, 6, 8-12.

11.Jain SK, Uppal RP, Garg BD (1992): Pharmacokinetics and urinary excretion of sulfadiazine in buffalo calves. Ann Rech Vet, 23, 389-393.

12. Kaya S, Bilgili A, Baydan E (1995): Ankara'nın merkez ve çevre ilçelerinden sağlanan yumurtalarda sülfonamid kalıntıları. AÜ Vet Fak Derg, 42, 143-147.

13. Kaya S, Baydan E, Bilgili A, Yarsan E, Şeker Y (1997): Etlik iliçlerde enrofloksasinin farmakokinetiği ve manganla enrofloksasin arasında emilme yönünden etkileşme. AÜ Vet Fak Derg, 43, 195-202.

14. Kaya S (2014): Farmakokinetik. 21-84 In: Kaya S (Ed), Veteriner Farmakoloji. Medisan Yayınevi, Ankara.

15. Kaya S (2013): Sülfonamidler. 439-453. In: Kaya S (Ed), Veteriner Farmakoloji. Medisan Yayınevi, Ankara.

16. Kayaalp OS (2018): Akılcıl Tedavi Yönünden Tıbbi Farmakoloji. Pelikan Yayıncılık, Ankara.

17.Löscher W, Fabbender CP, Veissing M, Kietzmann M (1990): Drug plasma levels following administration of trimethoprim and sulphonamide combinations to broilers. J Vet Pharmacol Therap, 13, 309-319.

18. Özkazanç AN, Kaya S (1983): Hayvanların pişmemiş yenilebilir dokularında sülfonamid analizi. AÜ Vet Fak Derg, 30, 624-638.

19. Reddy KS, Jain SK, Uppal RP (1988): Pharmacokinetics studies of sulphonamides in poultry. Indian J Anim Sci, 58, 437-439.

20. Reider J (1972): Quantitative determination of the bacteriostatically active fraction of sulfonamides and the sum of their inactive metabolites in the body fluids. Chemotherapy, 17, 1-21.

21. Resmî Gazete (10.06.1996 tarihli ve 22662 sayll1): Yemlik Preperat Ve Mineral Yemlerin Satış ve Tescil İslemlerinde Uyulması Gereken Hususlar Hakkinda Tebliğ.

22.Şanlı Y, Kaya S, Özakazanç N (1987): Tavukçulukta kullanılan bazı sülfonamid türevlerinin yumurtaya geçme özellikleri üzerinde araştırmalar. AÜ Vet Fak Derg, 34, 16-30. 
23.Şanlı Y (1988): Veteriner Farmakoloji. AÜ Vet Fak Yayınları, Ankara.

24. Uppal RP, Reddy KS, Jain SK (1988): Sulfadiazine plus trimethoprim a rational combination in poultry. Indian Vet, 65, 121-124.

25. Wagner JG (1975): Fundamentals of Clinical Pharmacokinetics. Drug Intelligence inc, Hamilton, Illionis.

26. Wang ZQ, Li HS, Xiao X, Wang JB (2016): Comparative Pharmacokinetic of Three Sulfadiazine Suspensions by Oral Administration in Chicken. JAS, 8, 122-129

27. Williams S (1984): Official Methods of Analysis of the Association of Official Analytical Chemists. Association of Official Analytical Chemists Inc, USA. 